\title{
INFORMAÇÃO E COMUNICAÇÃO NAS TEORIAS DE J. HABERMAS E N. LUHMANN
}

Flavio Beno Siebeneichler

\section{Resumo}

O presente trabalho está amparado na hipótese segundo a qual os conceitos de comunicação, informação e intersubjetividade constituem divisores de águas entre as teorias de Niklas Luhmann e Jürgen Habermas. Mesmo assim, e, inclusive, devido à distância que separa os dois projetos teóricos, eles podem ser tomados como perspectivas teóricas extremamente úteis para uma melhor compreensão do homem e da sua sociedade.

Palavras-chave: Conceito de Comunicação; Conceito de Informação; Conceito de Intersubjetividade.

\section{ABSTRACT}

\section{Abstract}

The present work is supported by the hypothesis that the concepts of communication, information and intersubjectivity are dividers between the theories of Niklas Luhmann and Jürgen Habermas. Even so, and even because of the distance separating the two theoretical projects, they can be taken as extremely useful theoretical perspectives for a better understanding of man and his society.

Keywords: Concept of Communication; Information Concept; Concept of Intersubjectivity. 


\section{PREÂMBULO}

O presente trabalho está amparado na hipótese segundo a qual os conceitos de comunicação, informação e intersubjetividade constituem divisores de águas entre as teorias de Niklas Luhmann e Jürgen Habermas. Mesmo assim, e, inclusive, devido à distância que separa os dois projetos teóricos, eles podem ser tomados como perspectivas teóricas extremamente úteis para uma melhor compreensão do homem e da sua sociedade.

Observação $n^{\circ}$ 1: Apesar da importância e da centralidade da noção de agir comunicativo e de questões referentes à comunicação, a teoria habermasiana não contem uma teoria abrangente sobre a comunicação nem sobre a informação. Ao vasculhar a multifacetada obra do autor encontrei um único texto explícito sobre comunicação em geral, de 24 páginas, o qual foi escrito em 1989 e publicado em 1991 na obra Textos e contextos (HABERMAS, 1991). E mesmo assim, esse texto versa preponderantemente sobre a comunicação em Charles S. S. Peirce, que é naturalmente uma das fontes do pensamento habermasiano.

Ante tal constatação, considerei de bom alvitre apresentar as questões envolvendo a comunicação, em Habermas, tomando, como uma folha de contraste, a teoria de sistemas sociais auto-referenciais, de Niklas Luhmann, que está construída sobre uma explícita teoria da comunicação.

Observação $n^{\circ} 2$ : Uma análise de textos representativos dos dois autores revela que eles pretenderam elaborar uma teoria da informação. Esta é sempre abordada como parte integrante da comunicação. Por esta razão, adotarei, aqui, o mesmo procedimento: a informação será abordada pelo viés da comunicação.

Observação $n^{\circ} 3$ : Fica patente que ambos possuem, apesar de divergências insuperáveis, pontos teóricos em comum. A própria Teoria do agir comunicativo (HABERMAS, 1984), habermasiana, apesar de sua declarada oposição ao funcionalismo luhmanniano, lança mão de motivos de pensamento sistêmicos, como é o caso, por exemplo, da figura da dupla contingência.

Observação $n^{\circ} 4$ : Para melhor compreensão do nosso tema, julgo adequado referir preliminarmente, e ainda que de modo sumário, as principais divergências e os pontos comuns aos dois pensadores. 


\section{PONTOS EM COMUM E DIVERGÊNCIAS ENTRE OS PROJETOS TEÓRICOS DE NIKLAS LUHMANN E JÜRGEN HABERMAS.}

Em primeiro lugar, pode-se observar que a teoria da diferenciação de sistemas sociais, delineada por Luhmann (1987a), numa radical perspectiva funcionalista e a teoria do agir comunicativo, de J. Habermas, analítica e, ao mesmo tempo, hermenêutica, constituem exemplos privilegiados e contrapostos de tentativas racionais elaboradas com o intuito de enfrentar os grandes problemas que preocupam a humanidade e a sociedade atual em geral.

Cumpre observar, ainda, o nível de abordagem no qual ambos se situam, uma vez que tanto Jürgen Habermas, como Niklas Luhmann, têm de ser interpretados numa dupla perspectiva, sociológica e filosófica. E tal exigência não deriva apenas do fato de ambos terem sido contemplados com o "Prêmio Hegel", conferido pela Sociedade Hegeliana a pensadores e filósofos cujas obras merecem destaque no mundo de hoje pela capacidade de traduzirem a sua época em pensamentos. Porquanto ambos fundam suas respectivas teorias sobre a sociedade, em última instância, na filosofia.

Não obstante isso, o radicalismo de suas concepções filosóficas acarreta como conseqüência quase natural uma divergência profunda na maneira de se compreender os princípios e as funções da filosofia.

\subsection{NIKLAS LUHMANN: A FILOSOFIA COMO TEORIA DA DIFERENÇA.}

No que respeita a Luhmann (1987a), ele consegue atingir o nível de uma teoria filosófica abstrata que segue rigorosamente o que recomenda aos outros, isto é, redução de complexidade. Ele tem na mira o que ele mesmo designa como planta baixa (Grundriss) de uma teoria sociológica universal, cujo domínio de objetos não reside mais, apenas, em fatos sociais detectáveis em um mundo empírico mediante observações diretas ou de primeira ordem, mas em um "mundo total" (Gesamtwelt) enquanto referido a uma diferença fundamental entre sistema e entorno a ser realizada mediante uma observação de segunda ordem.

Tal procedimento teórico pressupõe uma epistemologia naturalista destituída de princípios a priori. Por esta razão, mesmo quando apresenta a sua concepção como "superteoria" policêntrica e policontextual capaz de enfrentar a acentricidade do mundo e da sociedade, Luhmann (1987a), não exclui a possibilidade de outros princípios.

Ele distingue três níveis de análise:

- O nível dos sistemas. 
- O nível dos instrumentos, das máquinas, dos organismos, dos sistemas psíquicos e dos sistemas sociais.

- O nível das interações, das organizações e das sociedades (LUHMANN, 1987a, p. 12-16).

Convém lembrar que a teoria não pretende ser simples método de análise da realidade porquanto parte do pressuposto da existência preliminar de sistemas que se diferenciam de modo funcional e que exigem uma observação de segunda ordem (LUHMANN, 1987a, p. 30). Tal concepção se apóia sobre uma série de teses bastante questionadas, tais como:

- Os sistemas funcionais da sociedade são autônomos e se auto-regulam.

- Ao passo que a sociedade como um todo, isto é, a sociedade como sociedade mundial não consegue se auto-regular.

- Não existe um centro capaz de servir como ponto de referência para orientações práticas na sociedade.

- A construção da sociedade segue a linha de um entrelaçamento recursivo entre observações e descrições:

Todo observador moderno vê o que os outros observadores vêem; porém, ele também vê o que os outros observadores não conseguem ver no momento em que realizam sua observação; e ele também constata que eles não podem ver o que eles não conseguem ver (LUHMANN, 1987b, p. 5).

A questão que se levanta nesse momento é a seguinte: será que uma sociedade destituída de centro e que não consegue se auto-regular, pode, mesmo assim, criar estados próprios estáveis?

Luhmann (1987b), ilustra esse problema lançando mão da figura de um labirinto percorrido por ratos:

Há somente ratos no labirinto, os quais se observam uns aos outros e, por isso, jamais podem chegar a um consenso, quando muito, a estruturas sistêmicas. Não existe nenhuma operação de observação fora do labirinto ou do contexto. E é evidente que uma teoria que descreve esse estado de coisas tem de ser uma teoria para ratos. No labirinto, ela pode escolher um bom lugar para uma observação. Eventualmente ela pode enxergar mais do que outros, especialmente o que outros não vêem; mesmo assim, ela não pode deixar de ser observada (LUHMANN, 1987b, p. 6).

É bom notar, todavia, que o observador solitário luhmanniano inicia o seu trabalho observacional no labirinto lançando mão de uma diferenciação fundamental ou "basal" que pode ser tida como um verdadeiro imperativo categórico funcional: beginne mit 
einer Unterscheidung! "Para começar, esboce uma distinção". "Draw a distinction" (Georg Spencer Brown). E continue seu trabalho de observação diferenciando distinções! (LUHMANN, 1995).

Com isso fica claro que no início de tudo, isto é, no observatório fincado num labirinto percorrido por ratos, tudo é contingente. Torna-se necessária uma diferenciação destinada a reduzir complexidade. Ela se impõe mesmo sabendo que a complexidade não pode, em última instância, ser eliminada. Além disso, ninguém é capaz de dizer qual deva ser esta distinção inicial. A própria lógica limita-se, segundo Luhmann (1995), ao essencial e se cala quando inquirimos sobre a distinção a ser tomada como ponto de partida (LUHMANN, 1995, p. 375).

Daí o grande paradoxo da teoria funcional policêntrica: No início ela se vê confrontada com alternativas insuperáveis, com um "dentro" e um "fora", com um "e" e um "ou". Por exemplo, a diferença "homem e/ou mulher". Ela sabe que ambas as coisas existem e que é preciso decidir qual delas escolhemos como objeto de observação ou como tema.

Com isso, Luhmann (1975), faz jus ao fato de que o início de nossas observações é sempre contingente. Dito de outra forma: quando nos decidimos por um determinado começo descobrimos que haveria a possibilidade de iniciar de outra forma (LUHMANN, 1995, p. 374). (Isso fica muito claro no caso da arte: a incisão inicial de uma forma cria um limite entre um espaço marcado e outro não marcado).

Interessa aqui salientar que o imperativo categórico funcional leva Luhmann (1975), a substituir o conceito de "razão" pela idéia de um "operar com o auxílio de conceitos", o qual se processa através de diferenciações e diferenciação de distinções ao nível de uma observação de segunda ordem, a qual é capaz de observar as observações e as descrições dos observadores.

Em consonância com esta visão, Luhmann (1975), se auto-entende como um teórico da diferença. Segundo ele, no início de qualquer tipo de trabalho teórico não devemos tentar buscar simplesmente unidade ou coerência, apenas distinções que marcam diferenças.

\subsection{JÜRGEN HABERMAS: A FILOSOFIA COMO GUARDIÃ DA RACIONALIDADE E COMO INTERPRETE DO MUNDO DA VIDA.}

Já a filosofia de Jürgen Habermas segue um caminho bastante diverso. Apesar de sua reiterada modéstia pós-metafísica, ele propõe uma forma de filosofia igualmente revolucionária apoiada, porém, em linguagem comum e em racionalidade comunicativa. 
Convém frisar, no entanto, que Habermas, apesar de continuar preso ao conceito de razão e de sujeito, consegue, ao contrário de Luhmann, desvencilhar-se do paradigma mentalista da filosofia do sujeito: Ele considera que a razão é essencialmente comunicativa e pública. Não uma prerrogativa exclusiva de um sujeito privado ou de uma inteligência que apenas observa, opera ou calcula monologicamente:

Para sabermos se aquilo que fazemos no mundo ou se nossas representações do mundo são racionais, não temos outra saída a não ser a troca ou comunicação pública - liberta e libertadora - de argumentos sobre aquilo que experimentamos, pensamos ou pretendemos fazer [...] (WINGERT, 2001, p. 7).

Neste contexto, a filosofia aparece como uma guardiã da racionalidade e como uma intérprete mediadora e crítica do mundo da vida.

\section{OS CONCEITOS DE "COMUNICAÇÃO" E "INTERSUBJETIVIDADE" COMO DIVISORES DE ÁGUAS NAS TEORIAS DE J. HABERMAS E N. LUHMANN.}

\subsection{O CONCEITO DE COMUNICAÇÃO}

Em linhas bem gerais, a comunicação é definida por Habermas na linha lingüístico-pragmática de uma teoria da interação social ancorada em dois conceitos básicos: subjetividade e intersubjetividade.

Em segundo lugar, Habermas privilegia ações comunicativas que têm como pano de fundo um horizonte hermenêutico ou mundo da vida formador de contextos para processos racionais de entendimento. Tais processos de entendimento podem desdobrar-se em dois planos: o da comunicação trivial no espaço de um mundo da vida; e o de um discurso destinado a resgatar, por argumentos, pretensões de validade questionadas, isto é, quando o conteúdo informativo da atividade comunicativa é colocado sob suspeita.

Ao passo que Niklas Luhmann situa o conceito de comunicação - que ele define como um operar comunicativo - no paradigma funcionalista de sistemas auto-referenciais ou autopoiéticos. Ela aparece como processo de seleções de sentido autônomas, auto-referenciais e fechadas, as quais se destinam à manutenção dos limites dos sistemas dentro do seu entorno. Por esta razão, a operação básica da comunicação luhmanniana é paradoxal.

\subsection{O CONCEITO DE INTERSUBJETIVIDADE}




\subsubsection{O CONCEITO DE INTERSUBJETIVIDADE EM HABERMAS}

Para compreender adequadamente as implicações desse conceito na obra de Jürgen Habermas torna-se necessária uma referência à sociologia fenomenológica de Alfred Schütz (SCHUTZ, 1967), que, ao discutir as perspectivas abertas pela teoria husserliana, bem como os impasses intransponíveis nos quais ela desembocou, desistiu de qualquer tentativa visando fundamentar uma intersubjetividade pelo caminho da redução fenomenológica.

A melhor solução seria, segundo ele, tomar como um pressuposto o fato de que a intersubjetividade constitui um problema ineludível decorrente das características do próprio mundo da vida, não sendo, por esta razão, solucionável por nenhum tipo de análise teórica. Temos, pois, um conceito de intersubjetividade que é, ao mesmo tempo, ineludível e indemonstrável. Um paradoxo!

Entretanto, a incontornabilidade e a indemonstrabilidade do conceito de intersubjetividade abrem espaço para duas abordagens distintas e opostas, a saber:

- A interpretação da intersubjetividade como um "dado último", evidente a priori, que tem a ver com realizações fundantes de um sujeito que se vê constrangido a constituir e interpretar o mundo. Esta é a posição assumida por Martin Heidegger.

- A consideração da intersubjetividade como um "algo intermitente" que resulta de uma relação comunicativa frágil que se estabelece entre dois sujeitos, um Ego e um Alter, a qual pode se concretizar por meio de uma comunicação lingüística.

Jürgen Habermas se decide por esta segunda possibilidade de interpretação da intersubjetividade. E como primeira conseqüência, ele não pode mais tomar como ponto de partida a idéia fenomenológica de uma subjetividade fundada apenas em operações mentais solitárias de um sujeito que constitui e desoculta monologicamente o mundo. Também não pode aceitar a idéia do observador solitário no labirinto dominado por roedores. Para ele, a intersubjetividade é, ao mesmo tempo, pressuposto e resultado, intermitente, da linguagem comum que é base de qualquer processo social.

Convém salientar, no entanto, que Jürgen Habermas acrescenta um elemento fundamental à visão fenomenológica da intersubjetividade, dado o fato de que ele interpreta esse princípio à luz de um paradigma do agir comunicativo orientado por entendimento racional e pretensões de validade. E neste paradigma, Ego e Alter são tidos na conta de sujeitos que se socializam e se individuam mediante esse tipo específico de comunicação lingüística. Isso é possível, segundo ele, porque eles já se encontram previamente em mundos 
da vida estruturados lingüisticamente, os quais podem ser compartilhados de modo intersubjetivo (HABERMAS, 1988, 63-68).

\subsubsection{Niklas Luhmann e a Impossibilidade da Intersubjetividade.}

Para Luhmann (1987a), a intersubjetividade constitui algo improvável, quiçá impossível, dado o problema da dupla contingência. Por isso ele simplesmente abandona o conceito tradicional de intersubjetividade, o qual é, no entanto, adotado por Habermas.

$\mathrm{O}$ autor se desfaz desse conceito porque o considera problemático, um verdadeiro "não-conceito". Segundo ele, tal conceito se fundamenta na idéia de que a subjetividade e a intersubjetividade são co-originárias e pressupõem uma relação dialética entre Ego e Alter.

Ora, argumenta Luhmann (1987a), tal dialética apenas reproduz uma relação de alteridade na perspectiva de uma egoidade, isto é, na perspectiva do próprio sujeito.

Esse ponto pode ser compreendido de uma forma mais precisa quando se leva em conta o tema da dupla contingência.

\subsubsection{O Tema da Dupla Contingência}

O conceito de "dupla contingência" aparece inicialmente na obra conjunta organizada em 1951 por Talcott Parsons e Edward Shills, intitulada: Toward a General Theory of Action (PARSONS; SHILS, 1951):

Existe uma dupla contingência inerente à interação. De um lado, as gratificações de Ego são contingentes em sua seleção de alternativas disponíveis. De outro lado, porém, a reação de Alter será contingente tendo em vista a seleção de Ego e resultará de uma seleção complementar por parte de Alter (Cf. LUHMANN, 1987a, p. 148).

Ante a constatação dessa contingência, Parsons concluíra que nenhum tipo de agir pode acontecer caso Alter coloque seu agir na dependência do modo de agir de Ego e caso Ego pretenda acoplar seu comportamento ao de Alter.

Luhmann (1987a), reinterpreta esta dupla contingência parsoniana afirmando que ela está presente de modo virtual sempre que surge um sistema psíquico ou uma consciência capaz de experimentar sentido (LUHMANNM, 1987a, p. 151). As duas contingências eclodem sempre que um sistema psíquico se encontra com outro sistema psíquico ao qual atribui sentido, ou quando um sistema psíquico se defronta com um sistema social. E nesse caso, o problema da dupla contingência torna-se um problema de comunicação. 
$\mathrm{Na}$ seqüência, Luhmann (1987a), modifica e amplia o conceito da dupla contingência parsoniana tornando-a mais abstrata a ponto de configurá-la como um verdadeiro teorema. Ela passa a caracterizar algo que não é necessário nem impossível, isto é, algo que pode ser (foi ou será) como é, mas que também poderia ser de modo diferente. A fim de ilustrar esse conceito, ele lança mão do conceito "caixa-preta" (black Box): "Duas caixaspretas se encontram casualmente. Cada uma determina seu próprio comportamento mediante operações auto-referenciais altamente complexas no interior de seus próprios limites [...]" (LUHMANN, 1987a, p. 156).

É possível visualizar nelas redução de complexidade. Porquanto cada uma delas pensa que a outra faz o mesmo. Por esta razão, apesar dos esforços e do tempo dispendido, elas continuam intransparentes entre si.

Entretanto, mesmo quando operam de forma estritamente mecânica ou quando operam cegamente, elas conseguem agir melhor, uma em relação à outra, quando se atribuem mutuamente determinabilidade no âmbito de uma diferenciação, isto é, em uma relação sistema/entorno e quando passam a se observar mutuamente a partir desta diferença.

Nesta nova perspectiva, as caixas-pretas continuam separadas. Tampouco se compreendem melhor do que antes. Entretanto, elas podem concentrar-se naquilo que observam uma na outra, a saber: um "sistema-em-um-entorno". E desta forma elas aprendem a se observar de um modo auto-referencial, na perspectiva de um observador (sentado em um labirinto percorrido por ratos). Elas podem, além disso, tentar influenciar, mediante seu agir, tudo que observam.

\section{A COMUNICAÇÃo Á LUZ DA DUPLA CONTINGÊNCIA.}

\subsection{LUHMANN}

Luhmann (1995), toma como ponto de partida o fato de que geralmente a comunicação é caracterizada mediante a metáfora da transmissão (Übertragung). Dizemos que a comunicação transporta, transfere ou transmite notícias, mensagens ou informações de vários tipos, de um remetente ou emissor para um destinatário ou receptor.

Depreende-se deste uso que a essência da comunicação reside no ato da transferência (Mitteilung) ou ato comunicativo. Neste caso, o acento recai na habilidade daquele que comunica, transmite uma mensagem ou informa algo. Além disso, é sugerido que a informação transferida é idêntica tanto para o emissor como para o receptor. 
No entanto, a situação paradoxal das caixas-pretas, ou sistemas psíquicos, a qual é duplamente contingente, leva Luhmann (1995), a buscar outro tipo de abordagem para a comunicação. Ele a considera uma criação autônoma de "forma no medium de um sentido", isto é, uma realidade emergente que depende de seres vivos, mas que não pode ser atribuída a nenhum deles em particular nem à totalidade deles. Ela se constitui numa seqüência de transformações de sinais extraídos de outras comunicações. Por isso, ela constitui, em sentido estrito, um sistema próprio, autopoiético (LUHMANN, 1995, p. 20).

A comunicação se torna, nesse contexto, um processo auto-referencial de escolha de sentido que opera com uma diferença entre três elementos (LUHMANN, 1995, p. 194):

- informação;

- transmissão ou ato comunicativo;

- compreensão.

E neste caso, a própria comunicação processa tal diferença (LUHMANN, 1995, p. 209).

Dito de outra forma: a comunicação somente pode acontecer se Ego for capaz de distinguir as seleções e conseguir operar com o auxílio delas (LUHMANN, 1995, p. 198). Pode-se afirmar, pois, que a comunicação tem como meta organizar a acoplabilidade entre as caixas-pretas tornando provável aquilo que é altamente improvável: a acoplagem entre Alter e Ego!

\subsection{HABERMAS.}

Habermas toma como ponto de partida a interação social que é viabilizada por exteriorizações lingüísticas. (HABERMAS, 1988, p. 68-75). Tal interação também pode ser entendida como a solução de um problema de acoplagem entre as ações de Alter e de Ego. No caso de uma acoplagem bem sucedida haveria uma redução do espaço de possibilidades de escolha conflitantes.

Ora, existem dois tipos básicos de interação dependendo do modo como os planos de ação de Alter venham a ser acoplados aos de Ego (HABERMAS, 1988, p. 69):

- No primeiro caso, a linguagem comum é utilizada apenas como medium para a transmissão de informações (agir estratégico).

- No segundo caso, a linguagem é utilizada também como fonte de integração social ou de entendimento entre Alter e Ego (agir comunicativo). 
Isso significa que no próprio agir comunicativo podemos deparar-nos com séries de ações estruturadas teleologicamente. Entretanto, para haver uma acoplagem entre Alter e Ego, impõe-se uma mudança de atitude. Porquanto o medium da linguagem só pode exercer tal função de acoplagem quando consegue interromper os planos de ação comandados apenas pelo sucesso próprio (agir teleológico).

Com isso, as orientações egocêntricas de Alter ou de Ego são colocadas sob os limites estruturais de uma linguagem compartilhada intersubjetivamente, o que permite realizar uma mudança de perspectiva: os atores (Alter e Ego) abandonam momentaneamente o enfoque objetivador e operacional, orientado pelo telos do sucesso próprio, e adotam o enfoque performativo de um agente ou falante que pretende entender-se com uma segunda pessoa a respeito de algo no mundo.

Essa passagem para as condições do uso da linguagem orientado por entendimento é necessária para lograr acesso aos potenciais ou energias ilocucionárias de acoplagem inerentes à linguagem. Ao nível de um puro agir estratégico tais forças de acoplagem feneceriam, a linguagem e a fala encolheriam, retrair-se-iam e se estreitariam ajustando-se às dimensões de um simples medium para a transmissão de informações (HABERMAS, 1988, p. 72), o que é criticado pelo próprio Luhmann (LUHMANN, 1995).

\section{CONCLUSÃO}

Penso que as considerações lacônicas apresentadas validam a hipótese de trabalho levantada no início. Elas nos revelam que a comunicação é, mesmo que por razões distintas, o elemento fundamental de configuração de uma sociedade nos dois modelos teóricos sugeridos, isto é, nos moldes luhmannianos de uma constituição autorregulada e autopoiética de sistemas psíquicos; e nas dimensões habermasianas do espaço público intersubjetivo de uma sociedade radicalmente democrática e comunicativa.

No primeiro caso, quando a comunicação entra em cena surge um sistema que mantém uma relação sui generis e paradoxal com o seu entorno. Neste caso, ela é acessível enquanto informação e seleção de sentido por parte de um sistema psíquico.

No segundo, a comunicação trivial cotidiana entre pessoas comuns constitui o ponto de partida para uma troca ilimitada de experiências, informações e argumentos sobre três tipos de realidade: o mundo dos objetos e seres naturais, o complexo mundo social e o mundo inextricável dos sujeitos. 


\section{REFERENCIAS}

HABERMAS, Jürgen. Nachmetaphysisches denken: philosophische aufsätze. Frankfurt: Suhrkamp, 1988.

LUHMANN, Niklas. Soziale systeme: rundriss einer allgemeinen theorie. Frankfurt: Suhrkamp, 1987a.

- Soziologische Aufklärung 4: beiträge zur funktionalen differenzierung der gesellschaft. Opladen: Westdeutscher Verlag, 1987b.

Die wissenschaft der gesellschaft. Frankfurt.: Suhrkamp, 1992.

Die kunst der gesellschaft. Frankfurt: Suhrkamp, 1995.

PARSONS, Talcott; SHILS, Edward A. Toward a general theory of action. Cambridge: Harvard University Press, 1951.

SCHUTZ, Alfred. Phenomenology of the social world. Evanston: Northwestern University Press. 1967.

WINGERT, Lutz; GÜNTHER, Klaus (eds.). Die öffentlichkeit der vernunft und die vernunft der Öffentlichkeit: festschrift für Jürgen Habermas. Frankfurt: Suhrkamp, 2001. 